\title{
Impact of Spatial Scale on Remotely Sensed Evapotranspiration Estimates from Heterogeneous Land Surfaces
}

\author{
P. Teluguntla ${ }^{1}$, D. Ryu' ${ }^{1}$, B. George' ${ }^{1}$ and J.P. Walker ${ }^{2}$ \\ ${ }^{I}$ Department of Infrastructure Engineering, The University of Melbourne, Parkville, VIC, 3010 \\ ${ }^{2}$ Department of Civil Engineering, Monash University, Clayton, VIC, 3800 \\ Email:teluguntlasaradhi@gmail.com
}

\begin{abstract}
Remote sensing can provide estimates of spatially distributed actual evapotranspiration (ET) at different spatial scales. Methods that combine remotely sensed observations with other ground-based information on land and atmospheric properties usually allow improved estimates of spatially distributed evapotranspiration (ET) than when remotely sensed data are used alone. Spatial resolution of remotely sensed ET estimates depends on the specifications of the satellite instruments (e.g., $60 \mathrm{~m}$ for Landsat, $1 \mathrm{~km}$ for MODIS and $10 \mathrm{~km}$ for AVHRR). Since satellite sensors have different spatial, spectral and radiometric resolutions, it is essential to understand the consistency of ET estimates from different sensors. The main objective of this paper is to understand the spatial scaling effects of remotely sensed ET estimates from coarse resolution AVHRR data, through the analysis of MODIS data in a highly heterogeneous catchment.
\end{abstract}

This study was undertaken in the Musi catchment in the Krishna River Basin, India. The average land parcel size in this catchment is 0.5 ha with highly variable crops and land management practices. In this study, the Surface Energy Balance Algorithm for Land (SEBAL) was used to estimate spatially distributed evapotranspiration by combining ground-based metrological data and remotely sensed data from MODIS sensor. Observed pan evaporation data from weather station were used for validation of the $250 \mathrm{~m}$ resolution MODIS ET output, before up scaling to course resolution products. In order to quantify the difference in ET estimates originating solely from the observation scale, ET estimates were aggregated to the AVHRR scale using two different approaches. First, high-resolution ET was estimated at the original pixel resolution of MODIS and then aggregated to the coarser resolution scale (output up scaling). Second, ET estimated directly at the coarser resolution by aggregating the fine resolution input data to the coarse resolution scale (input up-scaling). The relationship between the sub-pixel-scale heterogeneity and scaling effects on ET estimate is investigated and other factors affecting the observed discrepancies between ET estimates from MODIS and AVHRR are discussed. Overall a $0.12 \mathrm{~mm}$ difference observed in daily ET between the two up scaled process at catchment scale analysis.

Keywords: Spatial scale, evapotranspiration, heterogeneous land surfaces 
Teluguntla et al., Impact of spatial scale on remote sensing evapotranspiration estimates from heterogeneous land surfaces.

\section{INTRODUCTION}

Evapotranspiration (ET) is the most essential and critical component of the spatial hydrology that returns surface and ground water to the atmosphere. Consequently, reliable accounting of terrestrial water resources depends on the accurate estimation of ET. There are number of methods available for estimation of ET using surface meteorological observations. However, such approaches provide point measurements only, covering merely a small portion of surface which cannot reflect the spatial distribution of ET due to the heterogeneity of land surfaces. Remote sensing data from satellite based sensors have the potential to provide detailed information on land surface properties and parameters at local to regional scales. Possibly one of the most important land surface parameters that can be derived from remote sensing is actual ET. Therefore, satellite remote sensing is a promising tool to better understand this heterogeneity. Methods that combine remotely sensed observations with other ground-based information on land and atmospheric properties usually allow improved estimates of spatially distributed evapotranspiration (ET) than when used alone (Moran et al. 1994; Bastiaanssen et al. 1998a). The multi-band satellite images can provide vegetation and thermal information, which is closely related with energy and heat transfer. With increased availability of satellite data products, there are a wide range of sensors providing vegetation and thermal information at different wave lengths and spatial resolutions. Therefore remote sensing data can be used to estimate the spatial distribution of actual evapotranspiration (ET) at different spatial scales.

Spatial resolution of remotely sensed ET estimates depends on the specifications of satellite instruments. Sensor selection depends on the scale of the study area to be analyzed, meaning there is always a tradeoff between frequency of the images (spatial extent) and spatial resolution. For large scale (basin wide) analysis, it is always difficult to get high resolution imagery continuously. Consequently, high resolution imagery cannot be depended upon for continuous monitoring of basin climatology. Therefore moderate to coarse resolution data must be relied upon through targeted analysis of high /moderate resolution data in order to understand the limitations. The absolute values of reflectance, and hence of the derived variables, differ between sensors. This is not only because of particular wavebands used from different sensors have different resolution, but also are not exactly the same position, may not have the same sensitivity. This is the reason why derived variables obtained from MODIS cannot be compared with that of AVHRR.

A number of studies have estimated ET from different satellite sensors including Landsat, ASTER, MODIS and AVHRR data with different spatial scales, but most of these studies were conducted for uniform crop fields or for specific crops. Kustas et al. (2004) and Li et al. (2008) used aggregated Landsat data, McCabe and Wood (2006) used data from Landsat-ETM, ASTER and MODIS independently to estimate land surface fluxes, allowing direct comparison of results across measurement resolutions. They found that while high resolution data accurately reproduced tower based retrievals, the coarser scale data showed poor agreement. However, they also found that the catchment average evapotranspiration was well maintained with all three satellite platforms.

The current study was conducted in the sub catchment of Krishna River Basin in India, where land cover is highly heterogeneous. The objective of this paper is to understand the spatial scaling effects of remotely sensed ET estimates from coarse resolution AVHRR-10km data through the analysis of MODIS data, by changing the scale of observation in the highly heterogeneous Musi catchment in India. In this study, the Surface Energy Balance Algorithm for Land (SEBAL) was used to estimate spatially distributed evapotranspiration by combining ground-based metrological data with remotely sensed data from MODIS, by changing the scale of observation (input resolution). In order to quantify the difference in ET estimates originating solely from the scale of observation, ET estimates were aggregated to the AVHRR scale using two different approaches; first, ET was estimated at the original pixel resolution of MODIS and then aggregated to the coarser resolution scale (output up scaling). In the second approach, ET was estimated directly at the coarser resolution by aggregating the fine resolution input data to the coarse resolution scale (input up-scaling). 
Teluguntla et al., Impact of spatial scale on remote sensing evapotranspiration estimates from heterogeneous land surfaces.

\section{DESCRIPTION OF DATA AND STUDY AREA}

\subsection{Study Area}

The current study is conducted in the Musi catchment of Krishna River Basin located in Southern India. Musi catchment(Figure 1) lies between longitudes $77^{\circ} 50^{\prime} \mathrm{E}$ to $79^{\circ} 43^{\prime} \mathrm{E}$ and latitudes $16^{\circ} 43^{\prime} \mathrm{N}$ to $17^{\circ} 53^{\prime} \mathrm{N}$. The total geographical area of the catchment is approximately 11,000 km2 (Source: Central Water Commission, Govt of India, http://www.cwc.nic.in/). The river originates in the Ananthagiri hills around 100km west of Hyderabad in Andhra Pradesh. The climate of Musi catchment is dominantly semi-arid with mean annual rainfall of $750 \mathrm{~mm}$ and $90 \%$ of the precipitation occurring during the monsoon months of June- October, meaning it is unevenly distributed both spatially and temporally. Mean annual maximum temperature is $32^{\circ} \mathrm{C}$ and minimum is $18^{\circ} \mathrm{C}$. The land use of the catchment is highly heterogeneous and has a relatively diversified cropping pattern. The average agriculture land parcel size is 0.5 ha. The land use consists of agriculture (rainfed, irrigation with surface water and ground water), forest and urban, barren and rocky areas. The major crops include rice followed by vegetables, sorghum, millets, cotton, chilies, maize, grams, ground nuts, sugar cane, and fodder grass.

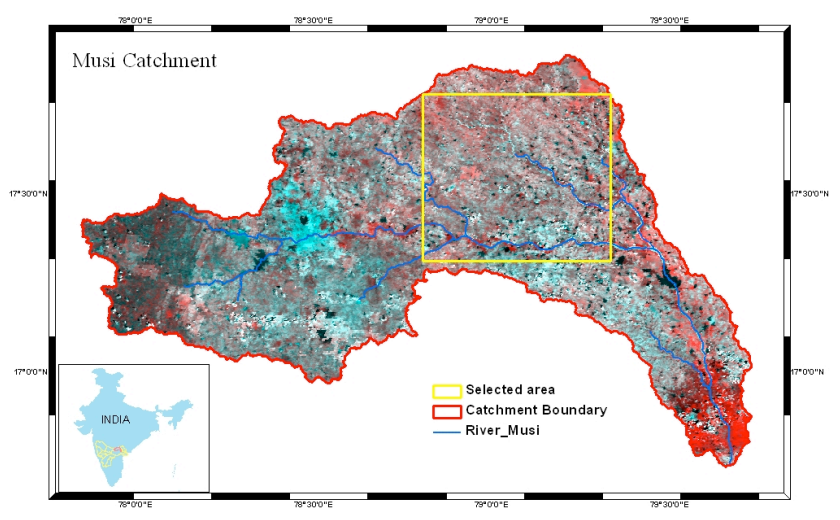

Figure 1. Location map of the Musi catchment, India. The river network is overlaid on a MODIS false color composite image.

\subsection{Satellite Data: MODIS}

The MODIS Terra sensor data (Table 2) is acquired originally in 36 narrow wavebands. MODIS provides different sets of land products, including different levels of surface reflectance and surface temperature products. The MOD09 product is computed from MODIS level 3 surface reflectance bands 1-7 (centered at $648 \mathrm{~nm}, 858 \mathrm{~nm}, 470 \mathrm{~nm}, 555 \mathrm{~nm}, 1240 \mathrm{~nm}, 1640 \mathrm{~nm}$, and $2130 \mathrm{~nm}$ ). The product is an estimate of the surface reflectance for each band, as it would have been measured at ground level if there were no atmospheric scattering or absorption. Original MODIS data is acquired in 12-bit (0 to 4096 levels), and is stretched to 16-bit (0 to 65536 levels). MOD 11A1 is computed from MODIS level 3 surface temperature products from the thermal bands. Two MODIS products (MOD09 and MOD11A1 tile ' $h 25 \mathrm{v} 07$ ') for the study area during the kharif peak period (September 29, 2000) were acquired and re-projected using MODIS Re-projection Tool (MRT). During this process, the digital numbers were converted into percent reflectance and surface temperature (LST) values using the scale factor provided in the user's manual. The split window technique was used to estimate surface temperature from the MODIS image. Split window algorithms take advantage of differential absorption in two close infrared bands, to account for the effects of absorption by atmospheric gases when multiple thermal bands are available (band31, band32). A land-use/land-cover map the catchment was generated using 8day composite time series of band1 and band 2 reflectance data.

Table 1 Characteristics of the MODIS bands used in this study

\begin{tabular}{|c|c|c|c|}
\hline Band (\#) & Wavelength range (nm) & Data final format & Potential Application \\
\hline 1 & $620-670$ & Reflectance & $\begin{array}{c}\text { Absolute Land Cover } \\
\text { Transformation, Vegetation } \\
\text { Chlorophyll }\end{array}$ \\
\hline 2 & $841-876$ & Reflectance & $\begin{array}{l}\text { Cloud Amount, Vegetation } \\
\text { Land Cover Transformation }\end{array}$ \\
\hline 31 & $10780-11280$ & Brightness temperature & $\begin{array}{c}\text { Fires \& Volcanoes, Surface } \\
\text { Temp. }\end{array}$ \\
\hline 32 & $11770-12270$ & Brightness temperature & $\begin{array}{c}\text { Cloud Height, Forest Fires \& } \\
\text { Volcanoes, Surface } \\
\text { Temperature }\end{array}$ \\
\hline
\end{tabular}


Teluguntla et al., Impact of spatial scale on remote sensing evapotranspiration estimates from heterogeneous land surfaces.

\subsection{Weather Station Data}

Weather information from a network of four meteorological station's is available for the Musi catchment, of which two stations are maintained by the Indian Metrological Department (IMD), and the other two are maintained by research institutions: International Crops Research Institute for Semi Arid Tropics (ICRISAT) and Central Research Institute for Dry land Agriculture (CRIDA). A complete set of data were collected from the four stations and used to calculate reference evapotranspiration using FAO-56 Monteith Model (Allen et al., 1998).

\section{METHODOLOGY}

\subsection{Model Description}

SEBAL is a widely used remote sensing ET model for estimation of spatially distributed evapotranspiration. It is an intermediate approach using both empirical relationships and physical parameterizations formulated by Bastiaanssen et al. (1998a), which has been evaluated by Bastiaanssen et al. (1998b) and many others. This model has been designed to calculate the energy partitioning at the regional scale with a minimum dependence on ground data. SEBAL computes a complete radiation and energy balance along with the resistances for momentum, heat and water vapor transport for each pixel (Bastiaanssen et al., 1998a, Bastiaanssen, 2000). The key input data for SEBAL consists of spectral radiance in the visible, near infrared and thermal infrared part of the spectrum (band1, band2, band31 and band32 of MODIS data). In addition to satellite images, the SEBAL model requires weather data parameters such as wind speed, humidity, solar radiation and air temperature. The primary basis for the SEBAL model is the surface energy balance. The instantaneous latent heat flux is calculated for each pixel of the image as a 'residual' of the surface energy budget equation by

$$
\lambda E=R_{\mathrm{n}}-\left(G_{0}+H\right),
$$

where $\lambda E$ is the latent heat flux, $R_{n}$ is the net radiation, $G_{0}$ is the soil heat flux and $H$ is the sensible heat flux. The latent heat flux describes the amount of energy consumed to maintain a certain crop evaporation rate. The surface albedo, surface temperature and vegetation index are derived from satellite measurements, and are used together to solve $R_{n}, G_{0}$ and $H$. The instantaneous latent heat flux ( $\lambda E$ ), is calculated as the residual term of the energy budget, and then used to compute the instantaneous evaporative fraction $(E \operatorname{Tr} F$ ). Instantaneous ET is computed from latent heat of vaporization and latent heat flux $\lambda E$ by

$$
E T_{\text {inst }}=3600 * \frac{\lambda E}{\lambda}
$$

where $E T_{\text {inst }}$ is the instantaneous ET (mm/hour), 3600 is the time conversion from seconds to hours and $\lambda$ is the latent heat of vaporization or heat absorbed when a kilogram of water evaporates $(\mathrm{J} / \mathrm{kg})$. The evaporative fraction $(E T r F)$ is computed from the instantaneous ET for each pixel to the hourly reference ET at the time of the image computed from weather data using FAO-56 Penman-Monteith method. ETrF is used to extrapolate ET from image time to 24 hour or longer periods. $E \operatorname{Tr} F$ values range from 0 to 1 . At a totally dry pixel, ET $=0$ and $E T r F=0$. Some pixels can occasionally have an ET slightly greater than $E T_{r}$ and therefore $E \operatorname{Tr} F>1$. Negative values for $E \operatorname{Tr} F$ can occur in SEBAL due to systematic errors caused by various assumptions made in the energy balance process. SEBAL (Idaho implementation) computes daily values of ET (ET24) by assuming that the instantaneous ET fraction computed is the same as the 24-hour average, according to

$$
E T_{24}=E T_{r F}^{*} E T_{r-24}
$$

where $E T_{r_{-} 24}$ is the cumulative 24 hour reference ET for the day of the image. 
Teluguntla et al., Impact of spatial scale on remote sensing evapotranspiration estimates from heterogeneous land surfaces.

\subsection{Up scaling process (Scaling Scheme)}

In the up-scaling process, two different procedures were evaluated. The first consisted of applying SEBAL method first and then aggregating the output variable (Daily ET). The second consisted of aggregating MODIS pixels of input variable (reflectance) to obtain pixels at the AVHRR-10km scale before SEBAL was applied (Figure 2). If the model is insensitive to an input parameter, aggregating the value with increasing scale will have little influence on model predictions. However, when the model does not operate linearly, the change in data aggregation could increase or decrease the model predictions of ET. Aggregation imagery were obtained by simple averaging. The simple averaging method calculates the arithmetic mean over an $n \times n$ window. Pixel values of satellite imagery are considered to be the integrated value over the corresponding area on the ground, so simple averaging is considered appropriate for aggregating remotely sensed images. The simple averaging method smoothes the original data values and therefore produces a "tighter" histogram than the original data set. Furthermore, aggregating a data set by simple averaging generally decreases the variance and also increases the spatial autocorrelation (French, 2001; Liang, 2004).

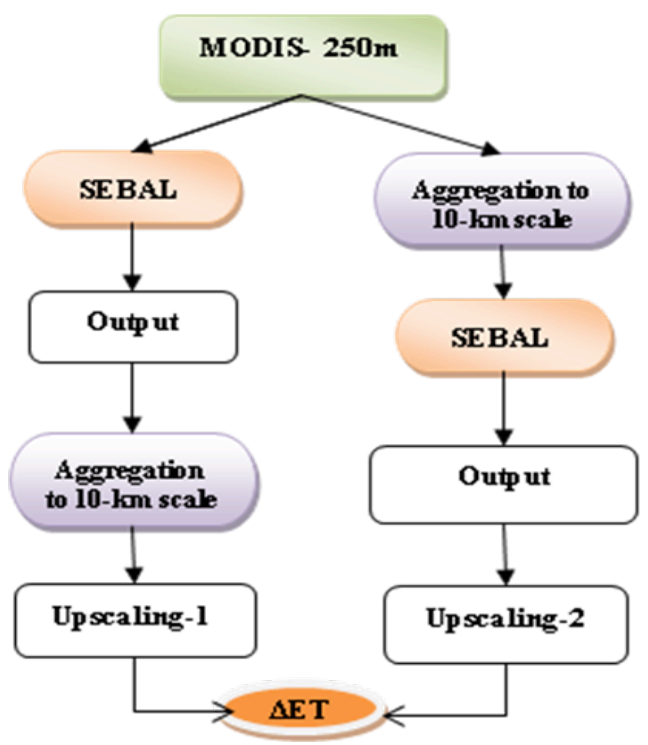

Figure 2. Flow chart showing the scaling approaches tested

Using the September 29, 2000 MODIS-250 m image together with routine meteorological data on temperature, humidity, wind speed and sunshine hours from the nearest stations, pixel-based daily actual ET is computed by solving the surface energy balance using Equations (2-5) for the selected study area (Figure 1). The daily actual ET-250 m map (Figure 3) clearly indicates spatial patterns of actual ET for various land use classes that include dry/barren lands, rangelands and agricultural crops both rainfed and irrigated. The computed daily actual ET ranges from 0.1 to $4.5 \mathrm{~mm}$ per day with a mean of $1.62 \mathrm{~mm} /$ day for the study area. The highest value of ET is observed for the water body (Table 2). In the process of SEBAL ET estimation, all the other heat fluxes are also estimated. The spatial distribution of heat fluxes and daily ET values estimated with $250 \mathrm{~m}$ spatial resolution are shown in the 1 st column of Figure 3 . The observed pan evaporation at the nearest station on the day of the image used in this study was $3.9 \mathrm{~mm} /$ day. The observed pan evaporation was compared with estimated ET at a water body pixel near to the weather station, which shows $4.2 \mathrm{~mm} / \mathrm{day}$, which is $0.3 \mathrm{~mm}$ /day more than the observed data.

In the second step, all the output parameters estimated with $250 \mathrm{~m}$ spatial resolution are up scaled to $10 \mathrm{~km}$ resolution (output up-scaling). Due to aggregation process, the range of output values was decreased and the extreme values were eliminated. Some of the hot spots in surface temperature and NDVI were disappeared. Consequently the scaled outputs translate into lower variability of the heat fluxes. The $10-\mathrm{km}$ up scaled actual ET ranges from 0.99 to $2.38 \mathrm{~mm}$, with mean value of $1.62 \mathrm{~mm}$ per day. Moreover, the net radiation flux range became narrow; the value ranged between 465 and $496 \mathrm{~W} / \mathrm{m}^{2}$. Similarly the other fluxes also. The spatial distributions of up scaled outputs (output up scaling) of surface fluxes and daily ET are shown in the second column of Figure 3 with the statistics shown in Table 2.

In the third step the scale of observation (input information) changed, the original MODIS-250 $\mathrm{m}$ remote sensing data are up scaled to $10 \mathrm{~km}$ scale using the simple averaging method. The up scaled reflectance values were used as input for ET estimation. This is similar to the procedure that was used in step 1 . The computed daily actual ET values at $10 \mathrm{~km}$ ranged from 0.1 to $3.1 \mathrm{~mm} /$ day with a mean of $1.5 \mathrm{~mm} /$ day. The actual ET range has been increased when compared with the output up scaled 10-km ET values and decreased when compared with $250 \mathrm{~m}$ scale ET values. The range of sensible heat flux and latent heat flues are varied when compared both up scaled $10 \mathrm{~km}$ outputs. Overall the difference observed in daily ET between the two up scaled process is $0.12 \mathrm{~mm} /$ day. 
Teluguntla et al., Impact of spatial scale on remote sensing evapotranspiration estimates from heterogeneous land surfaces.

Table 2 Variation of min, mean and max values of surface temperature and heat fluxes of three different scales observed in this study.

\begin{tabular}{|c|c|c|c|c|c|c|c|c|c|}
\hline & \multicolumn{3}{|c|}{ MODIS-250 m } & \multicolumn{3}{|c|}{$\begin{array}{c}\text { Output-up scaling } \\
10 \mathrm{~km}\end{array}$} & \multicolumn{3}{|c|}{$\begin{array}{c}\text { Input up scaling } \\
10 \mathrm{~km}\end{array}$} \\
\hline & Min & Max & Mean & Min & Max & Mean & Min & Max & Mean \\
\hline $\begin{array}{l}\text { LST } \\
\text { (Kelvin) }\end{array}$ & 301 & 314 & 308 & 305 & 310 & 308 & 305 & 310 & 308 \\
\hline $\begin{array}{l}\mathbf{R N} \\
\left(\mathbf{W} / \mathbf{m}^{2}\right)\end{array}$ & 163 & 664 & 481 & 465 & 496 & 481 & 486 & 517 & 502 \\
\hline $\begin{array}{l}\text { Soil heat flux } \\
\left(\mathbf{W} / \mathbf{m}^{2}\right)\end{array}$ & 26 & 103 & 76 & 67 & 81 & 76 & 71 & 87 & 80.5 \\
\hline $\begin{array}{l}\text { Sensible heat flux } \\
\left(\mathrm{W} / \mathbf{m}^{2}\right)\end{array}$ & 140 & 435 & 257 & 210 & 297 & 257 & 89 & 398 & 250 \\
\hline $\begin{array}{l}\text { Latent heat flux } \\
\left(\mathbf{W} / \mathbf{m}^{2}\right)\end{array}$ & 1 & 432 & 148 & 87 & 219 & 148 & 1 & 356 & 171 \\
\hline $\begin{array}{l}\text { 24H-ET } \\
(\mathrm{mm} / \mathrm{day})\end{array}$ & 0.1 & 4.5 & 1.62 & 0.99 & 2.38 & 1.62 & 0.1 & 3.1 & 1.5 \\
\hline
\end{tabular}
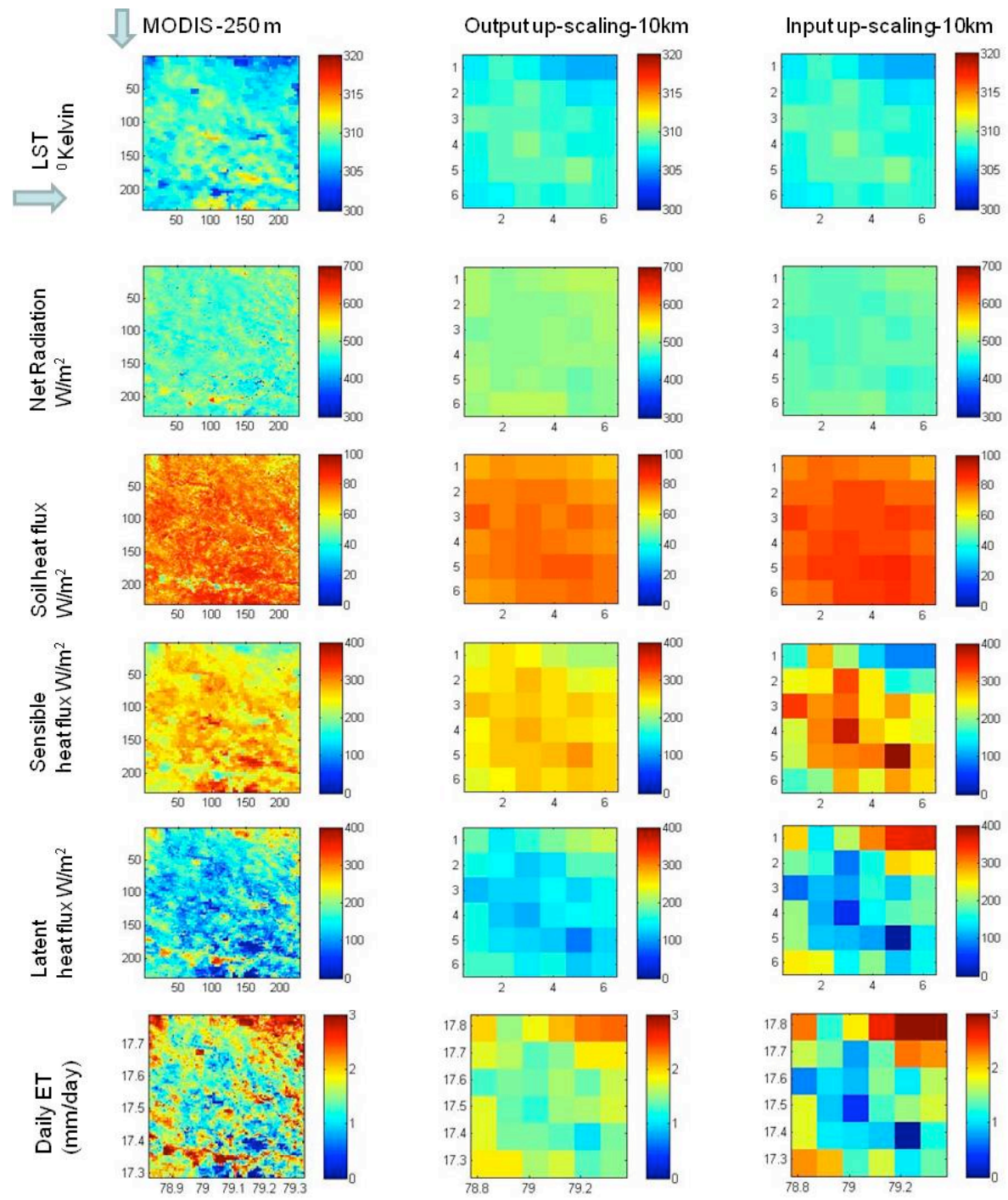

Figure 3. Comparison of spatial distribution of surface temperature, heat fluxes estimated at 3 scales; $250 \mathrm{~m}$ input resolution (left), output upscaling-10km (middle) and input up- scaling 10-km (right). 
Teluguntla et al., Impact of spatial scale on remote sensing evapotranspiration estimates from heterogeneous land surfaces.

The results of relative difference analysis among two up scaling process, large variation observed in the areas where the hot and cold pixels identified in the $10 \mathrm{~km}$ input up-scaling estimates; this is due to one of the limitation of SEBAL methodology. The daily ET estimated from input up-scaling process shows lower value than the output up-scaling. The differences are mainly originating from sensible heat flux estimations: because of estimation of sensible heat flux in SEBAL model scaling between hot and cold pixels. To quantify the scaling effect on ET estimation, the intermediate scales also verified by changing the input scale from 250 $\mathrm{m}$ to $1 \mathrm{~km}, 2 \mathrm{~km}$, and $5 \mathrm{~km}$ before $10 \mathrm{~km}$ scale is executed. There is no strong relation observed for the intermediate scales, but the average ET values across the catchment are decreasing when compared with the original input resolution.

\section{CONCLUSIONS}

In this study to understand the spatial scaling effects of remotely sensed ET estimates from coarse resolution data, two up scaling procedures were evaluated using SEBAL model with MODIS data. The impact of increasing spatial resolution results in the disappearance of some locations with extreme surface temperature and NDVI values. Consequently, the variability in the surface heat fluxes is reduced. The relative difference analysis among two up scaling processes shows a large variation in the areas where the hot and cold pixels are identified in the $10 \mathrm{~km}$ input up-scaling estimates. However, the aggregate of ET estimates at catchment scale shows agreed values. Even though the input resolution is coarser, ET estimates with $10 \mathrm{~km}$ input spatial resolution data is quite useful in the absence of high resolution data for continuous monitoring of basin climatology.

\section{ACKNOWLEDGEMENT}

The authors would like to thank Australian Centre for International Agricultural Research for sponsoring the research under John All Write Fellowship. The authors would like to thank Indian Meteorological Department (IMD), International Water Management Institute (IWMI) and Central Research Institute for Dry land Agriculture (CRIDA) for providing weather data.

\section{REFERENCES}

Allen, R., Pereira, L.A., Raes, D., Smith, M. (1998). Crop evapotranspiration guidelines for computing crop water requirements. FAO Irrigation and Drainage Paper No. 56, FAO, Rome.

Bastiaanssen, W. G. M., M. Menenti, et al. (1998a), A remote sensing surface energy balance algorithm for land (SEBAL): Part I Formulation. Journal of Hydrology 213(1-4): 198-212.

Bastiaanssen, W. G. M., Pelgrum, H., Wang, J., Ma, Y., Moreno, J.F., Roerink, G.J. van der Wal, T. (1998 b) A remote sensing surface energy balance algorithm for land (SEBAL): Part II Validation. Journal of Hydrology, 213(1-4): 213-229.

Bastiaanssen, W. G. M. (2000). SEBAL-based sensible and latent heat fluxes in the irrigated Gediz Basin, Turkey. Journal of Hydrology 229(1-2): 87-100.

Kustas, W. P., F. Li, et al. (2004). Effects of remote sensing pixel resolution on modeled energy flux variability of croplands in Iowa. Remote Sensing of Environment 92(4): 535-547.

Li, F., W. P. Kustas, et al. (2008). Effect of remote sensing spatial resolution on interpreting tower-based flux observations. Remote Sensing of Environment 112(2): 337-349.

McCabe, M. F. and E. F. Wood (2006). Scale influences on the remote estimation of evapotranspiration using multiple satellite sensors. Remote Sensing of Environment 105(4): 271-285.

Moran, M. S., Kustas, W. P., et al. (1994). Use of ground-based remotely sensed data for surface energy balance evaluation of a semi-arid rangeland. Water Resource Research 30: 1339-1349. 